\title{
Pengembangan Teknologi IoT Melalui Metode Demonstrasi dan Ekperimen Bagi Siswa SMA X di Kota Bandung
}

\section{Audyati Gany, Erwani Merry Sartika, Daniel Setiadikarunia, Novie Theresia Br. Pasaribu, Enrico}

\author{
Universitas Kristen Maranatha \\ audy.gany@gmail.com
}

\begin{abstract}
:
Community service is one of the Tri Dharma Colleges that must be carried out by higher education institutions no exception for Maranatha Christian University. Community-based devotional activities provide additional knowledge of Internet of Things (IoT) technology to high school students of class 12 science SMA X Bandung. The topic of community service activities this time is in accordance with the agreement of cooperation between the SMA X Bandung and the Electrical Engineering Study Program of Maranatha Christian University which coincided with the initial debriefing activity of the new academic year, namely by providing knowledge of IoT technology and its application to students of SMA X Bandung so that students can know and understand the development of IoT technology that is growing rapidly at this time. The material provided in community service activities is the introduction of IoT, the basic electronic components, the introduction of Arduino, the application of IoT, and the Blynk application for IoT. The training methods used are tutorials and practices, with $70 \%$ of the practice in the demonstration and experimental methods. Participants in this activity gain knowledge and understanding of IoT technology, can realize a simple IoT application, and can realize IoT using the Blynk application on a smartphone.
\end{abstract}

Keyword: IoT, Demonstration Method, Experiment Method

\section{Pendahuluan}

Pengabdian kepada masyarakat merupakan salah satu dari Tri Dharma Perguruan Tinggi yang wajib dilaksanakan oleh perguruan tinggi tidak terkecuali bagi Universitas Kristen Maranatha. Kegiatan pengabdian kepada masyarakat yang dilaksanakan adalah untuk memberi tambahan pengetahuan kepada masyarakat. Kegiatan Pengabdian kepada Masyarakat dengan topik peningkatan pengetahuan teknologi Internet of Things dan aplikasinya kali ini diberikan bagi siswa kelas 12 
142 | Pengembangan Teknologi IoT Melalui Metode Demonstrasi dan Ekperimen

IPA, SMA X Bandung sesuai dengan kesepakatan kerjasama pihak SMA X Bandung dengan Program Studi Teknik Elektro Universitas Kristen Maranatha. SMA X Bandung sebagai institusi pendidikan berkeinginan agar siswa-siswinya dibekali juga dengan pengetahuan teknologi yang sedang berkembang pesat saat ini, salah satunya adalah Internet of Thing (IoT), sehingga diharapkan siswa-siswa SMA X Bandung dapat mengikuti perkembangan teknologi terkini.

Setiap permulaan Tahun Ajaran baru, sekolah mempunyai program kerja pembekalan bagi siswa, yang berkaitan dengan pengenalan kampus (sekolah) bagi setiap siswa yang baru masuk di sekolah tersebut, baik pengenalan lingkungan sekolah maupun pembelajaran yang dilakukan sekolah itu. Bagi siswa yang masuk dikelas 11 dan 12, sekolah juga mempunyai program kerja pembekalan yang sesuai dengan rencana kegiatan sekolah pada tahun ajaran yang akan dijalani. Pihak sekolah melihat bahwa sangatlah perlu para siswa dibekali dengan teknologi yang sedang tren saat ini (Sinta Dameria Simanjuntak, 2019). Untuk itu sekolah membutuhkan topik yang berkaitan dengan perkembangan teknologi yang sedang tren itu untuk menjadi bahan pembekalan siswa. Kebutuhan sekolah untuk memotivasi siswanya agar siswa mempunyai ilmu pengetahuan dan teknologi yang sedang tren, siswa pun perlu dibekali dengan wawasan dan pengetahuan yang salah satunya adalah program pembekalan ilmu pengetahuan dan teknologi. Untuk awal tahun ajaran 2019/2020, dipilih teknologi IoT dengan harapan siswa dapat mulai merancang serta menerapkan IoT dalam kehidupan keseharian siswa.

Bentuk Kerjasama yang dilakukan oleh Program Studi Teknik Elektro Universitas Kristen Maranatha adalah memberikan pelatihan dan pendampingan pengenalan Teknologi IoT dan aplikasinya yang direalisasikan dalam bentuk kegiatan Pengabdian Kepada Masyarakat dengan salah tujuan adalah untuk meningkatkan kemampuan siswa dalam memahami dan mempelajari Teknologi IoT, yang pada akhirnya siswa mempunyai bekal kemampuan untuk menerapkan teknologi dalam keseharian mereka. 
Teknologi Internet Of Things (IoT) merupakan teknologi dengan konsep yang bertujuan untuk memperluas manfaat dari konektivitas internet (Atoasi, 2018). Internet dikenal sebagai jaringan yang menghubungkan manusia dengan informasi. Konsep awal dari jaringan Internet mengalami perkembangan yang sangat pesat, karena saat ini bukan hanya komputer dan telepon saja yang dapat terhubung, melainkan sudah banyak obyek lain yang dapat mengirim dan menerima data melalui internet yang sering disebut dengan Internet of Things (IoT) (Meutia, Teknik, \& Syiah, 2017). Perkembangan ini memberikan banyak kesempatan dan peluang pada berbagai sisi kehidupan masyarakat (Meutia et al., 2017). Forum IoT Indonesia memprediksi potensi pasar IoT Indonesia tahun 2020 mencapai sekitar 35 miliar dolar (Kusumawati, Winarko, Wahab, \& Pradono, 2017).

Internet of Things merupakan perkembangan keilmuan yang sangat menjanjikan untuk mengoptimalkan kehidupan berdasarkan sensor cerdas dan peralatan pintar yang bekerjasama melalui jaringan internet (Junaidi, 2016). IoT merupakan paradigma yang menyatakan bahwa setiap objek dapat digunakan sebagai alat untuk mengidentifikasi dan mengindera, selama objek terhubung dengan jaringan telekomunikasi serta mampu melakukan komunikasi dengan peralatan lain yang terhubung dengan internet (Informatika, Penelitian, Daya, \& Pos, 2016). Untuk itu bagi pemula diperlukan pemahaman dasar tentang komponen-komponen penunjang yang dipelajari dan digunakan dalam implementasi IoT.

Internet of Things (IoT) merupakan suatu jaringan yang menghubungkan berbagai objek yang memiliki identitas pengenal serta alamat IP, sehingga dapat saling berkomunkasi dan bertukar informasi mengenai dirinya maupun lingkungan yang diindera. Objek dalam IoT dapat menggunakan maupun menghasilkan layanan-layanan yang ada dan saling terintegrasi untuk mencapai suatu tujuan bersama (Utami, Arimbawa, \& Bimantoro, 2019). 
Internet of Things (IoT) merupakan sebuah konsep yang bertujuan untuk memperluas manfaat dari konektivitas internet yang tersambung secara terus menerus. Internet of Things (IoT) mengacu pada benda yang diidentifikasi secara unik sebagai repservasi virtual dalam struktur berbasis internet. Internet of Things (IoT) sebagai sebuah infrastruktur jaringan global, yang menghubungkan bendabenda fisik dan virtual melalui eksploitasi data capture, kemampuan komunikasi dengan sensor dan koneksi sebagai pengembangan layanan. Dalam hal tersebut dapat disimpulkan bahwa IoT mengacu pada suatu benda yang nantinya benda tersebut akan berkomunikasi antara satu dengan yang lain melalui sebuah jaringan internet. Salah satu dari penerapan IoT adalah pada kendali lampu (Kusumaningrum, Pujiastuti, \& Zeny, 2017).

Perkembangan industri menuju industry 4.0, menuntut masyarakat untuk dapat mengikuti perkembangan teknologi tersebut agar masyarakat tidak tersisih dalam persaingan mendapatkan pekerjaan. Untuk memberdayakan masyarakat agar dapat mengikuti perkembangan teknologi, dapat dilakukan dengan pemberian pelatihan dan pembinaan yang berkesinambungan. Pembinaan ini dapat dilakukan oleh perguruan tinggi sebagai salah satu bentuk kegiatan pengabdian kepada masyarakat. SMA X Bandung sebagai institusi pendidikan tidak mau ketinggalan sehingga sangat berkeinginan agar siswa-siswanya dibekali juga dengan pengetahuan perkembangan teknologi yang sedang berkembang pesat saat ini salah satunya adalah Internet of Thing (IoT), dengan harapan siswa-siswi SMA X Bandung dapat mengenal dan mengikuti perkembangan teknologi terkini. Dalam merealisasikan keinginan tersebut, SMA X Bandung bekerjasama dengan Program Studi Teknik Elektro Universitas Kristen Maranatha untuk membantu memberikan pelatihan atau lokakarya kepada para siswa kelas 12 IPA dalam memahami teknologi Internet of Things. Pemahaman Internet of Things dan Aplikasinya, secara mendasar perlu ditunjang dengan pemahaman komponen-komponen penunjang teknologi Internet of Things, sehingga dengan kemampuan pemahaman 
tersebut peserta akan mempunyai kemampuan untuk merealisasikan aplikasi sederhana dari teknologi Internet of Things.

Dalam tujuan untuk membuat peserta terlibat secara aktif, maka pelatihan ini dimulai dengan metode tutorial yang bertujuan untuk memberikan pengantar awal pengenalan tentang teknologi ini. Metode tutorial/ceramah merupakan metode yang sangat umum digunakan oleh para pengajar/instruktur karena metode tutorial adalah suatu bentuk penyampaian yang dilakukan secara lisan kepada para peserta, walau kadang metode tutorial ini dapat menimbulkan kebosanan. Untuk mengatasi kemungkinan peserta (siswa) menjadi bosan, maka pelatihan ini disertai pula dengan metode demonstrasi, metode eksperimen dan latihan.

Metode demontrasi adalah metode pembelajaran dengan cara memperagakan, barang, kejadian, aturan, serta urutan melakukan sesuatu kegiatan baik secara langsung maupun melalui penggunaan media pengajaran yang relevan dengan pokok bahasan atau materi yang sedang disajikan. Metode demonstrasi adalah metode penyajian pelajaran dengan memperagakan dan mempertunjukkan kepada siswa tentang suatu proses, situasi atau benda tertentu, baik sebenarnya atau hanya sekedar tiruan, yang kemudian dapat diikuti dengan memberi kesempatan pada peserta (siswa) mengikuti urutan kerja yang dipandu pula oleh instruktur (pengajar). Walaupun dalam proses demonstrasi peran siswa hanya sekedar memerhatikan akan tetapi demonstrasi dapat menyajikan bahan pelajaran lebih konkrit. Metode ini cukup efektif untuk diterapkan, karena akan membantu siswa untuk memperhatikan dan belajar menerapkan dengan melakukan pengulangan langkah-langkah dari apa yang dilihat/ didemontrasikan dan memberi kesempatan pada siswa untuk berusaha berfikir dalam mengikuti proses yang dilakukan. Metode ini biasanya lebih menarik dan membuat siswa lebih fokus terhadap materi pelatihan.

Dalam strategi pembelajaran, demonstrasi dapat digunakan untuk mendukung keberhasilan strategi pembelajaran ekspositori dan inkuiri. Metoda demonstrasi adalah pertunjukan tentang proses terjadinya suatu peristiwa atau 
benda sampai pada penampilan tingkah laku yang dicontohkan agar dapat diketahui dan dipahami oleh siswa secara nyata atau tiruannya. Tujuan pengajaran menggunakan metode demonstrasi adalah untuk memperlihatkan proses terjadinya suatu peristiwa sesuai materi ajar, cara pencapaiannya dan kemudahan untuk dipahami oleh siswa dalam pembelajaran dikelas (Ervarica, 2015).

Metode eksperimen dan latihan adalah metode yang dilakukan dengan dibarengi kegiatan praktik dan mencoba menerapkan sesuai dengan arahan atau petunjuk yang diberikan oleh instruktur atau pengajar. Disamping itu instruktur pun dapat memberikan satu kasus/ percobaan yang harus dipikirkan oleh siswa untuk jalan penyelesaiannya. Para siswa peserta pelatihan ini selain mendapat panduan dan arahan dari instruktur, mereka pun didampingi oleh asisten yang mengamati cara kerja siswa dan siap membantu bila siswa mengalami kebuntuan ataupun mengalami kendala penyelesaiannya. Metode pembelajaran ini dilakukan dengan cara melatih keterampilan (soft skill) para siswa karena dalam metode eksperimen dan latihan ini diperlukan ketekunan, ketelitian siswa dalam merancang dan melakukan.

Penggunaan metode eksperimen dapat mengembangkan berbagai kemampuan kognitif, afektif dan psikomotor siswa karena dengan metode eksperimen siswa akan melakukan kegiatan seperti mempelajari cara-cara penggunaan alat dan bahan, berusaha mencari dasar teori yang relevan, mengamati percobaan, menganalisa dan menyajikan data, dan menyimpulkan hasil percobaan (Maulidar, 2013).

Secara umum, perkembangan teknologi IoT, sangat menarik bagi kaum muda yang dalam kategori saat ini adalah generasi tingkat SMA dan SMK, memberi pandangan bagi mereka untuk melakukan sesuatu yang bermanfaat bagi kehidpan mereka saat ini dan mendatang. 


\section{Metode}

Metode pendampingan yang digunakan sebagai upaya penngkatan daya serap siswa SMA X di Kota Bandung dalam mempelajari teknologi IoT adalah Participatory Action Research (PAR) merupakan metode yang melibatkan peserta secara aktif, yang selalu berhubungan antara partisipasi, riset dan (Afandi, 2015), mengkaji tindakan yang sedang berlangsung adalah dalam rangka melakukan perubahan ke arah yang lebih baik.

Gambaran awal diperoleh dengan dilakukannya pertemuan dan wawancara terhadap pihak SMA X Bandung, agar diperoleh gambaran tentang tujuan dan apa yang menjadi kebutuhan dan harapan pihak SMA X Bandung, yang kemudian oleh Program Studi Teknik Elektro Universitas Kristen Maranatha menindaklanjuti dengan perancangan materi pembinaan dan penyusunan jadwal pelaksanaannya (Gambar 1), memperlihatkan tahap awal Kerjasama, yaitu adanya pertemuan, wawancara dan diskusi antara pihak SMA X Bandung dengan Pihak Program Studi Teknik Elektro Universitas Kristen Maranatha.
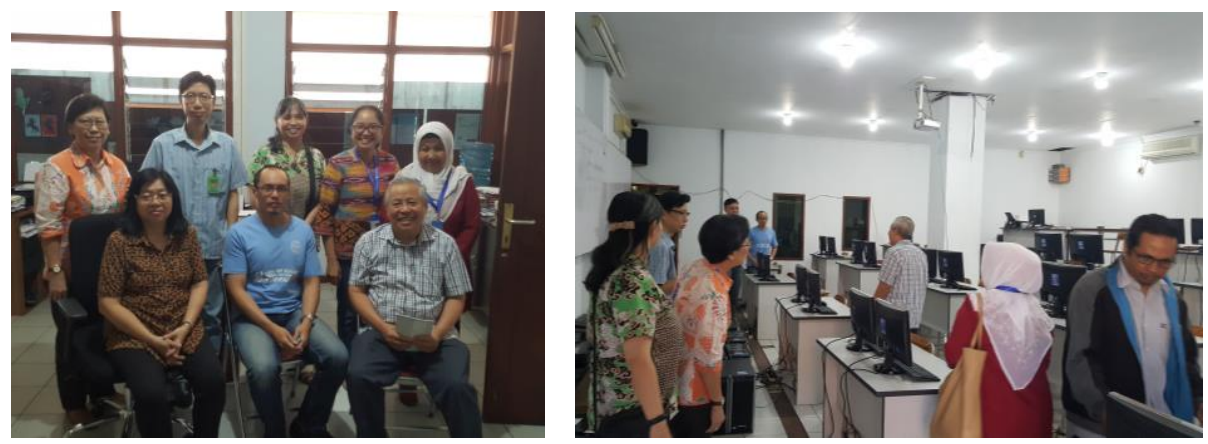

Gambar 1. Pertemuan dengan pihak SMA X Bandung

Metode yang digunakan dalam kegiatan ini dimulai dengan metode tutorial, (Gambar 2.), yang disertai dengan peragaan perakitan rangkaian IoT dan bagaimana pembuatan programnya, kemudian dilanjutkan dengan praktik pembuatan rangkaian IoT oleh tiap siswa peserta, (Gambar 3). Praktik merakit rangkaian dan pembuatan program sesuai dengan penjelasan yang disampaikan oleh nara sumber (instruktur) dengan didampingi oleh asisten yang membantu 
perakitan dan pembuatan program tersebut. Pendampingan dilakukan dengan perbandingan 1 asisten untuk 4 orang peserta, (Gambar 4).

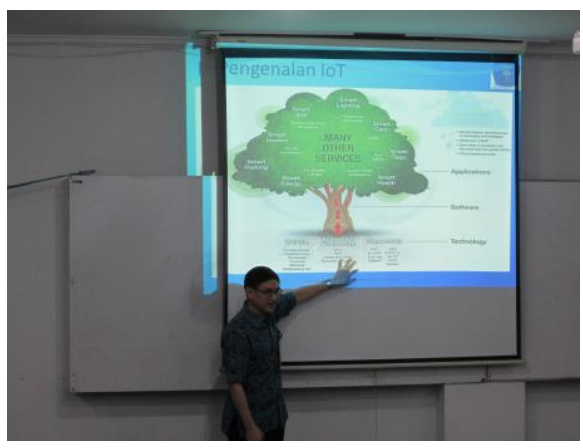

Gambar 2. Tutorial oleh instruktur

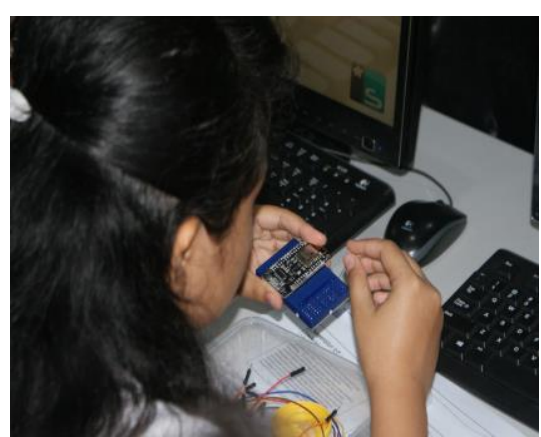

Gambar 3. Praktik oleh siswa

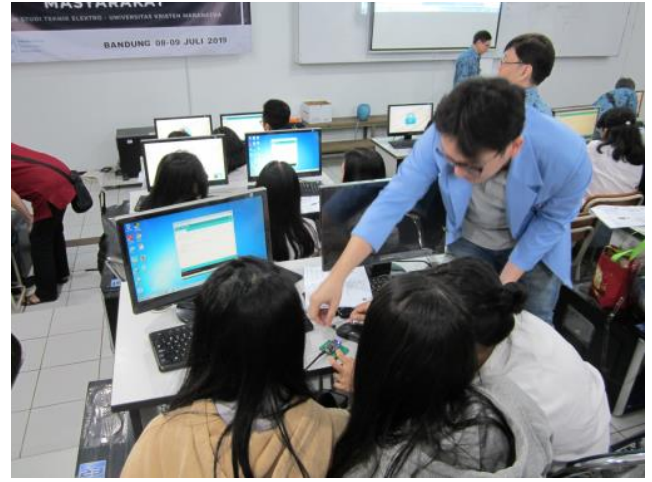

Gambar 4. Pendampingan oleh asisten untuk membantu siswa

Pelatihan ini dilakukan selama 2 (dua) hari, dengan pembagiannya adalah pada hari ke satu, peserta mendapat teori pengantar dari IoT dan penjelasan bagaimana merakit rangkaian pendukung dan membuat program untuk menjalankan proses yang diinginkan. Pelatihan hari kedua, peserta mendapatkan materi tentang bagaimana mengaplikasikannya melalui jaringan internet dengan menggunakan program Blynk, agar proses-proses yang diinginkan dapat dipantau melalui perangkat gawai dari jarak jauh.

Materi yang diberikan dalam kegiatan Pengabdian kepada Masyarakat (PkM) ini berupa teori dasar dari teknologi Internet of Things (IoT) yang 
disampaikan secara metode tutorial/ceramah oleh instruktur, kemudian dilanjutkan dengan panduan untuk latihan dan praktik cara menggunakan beberapa komponenkomponen penunjang dan aplikasi Blynk untuk penerapan teknologi Internet of Things.

\section{Hasil dan Diskusi}

Pelaksanaan Kegiatan Pengabdian kepada Masyarakat (PkM) dilakukan pada tanggal 8 dan 9 Juli 2019 yang dilaksanakan di Laboratorium Komputer SMA $\mathrm{X}$ Bandung. Kegiatan diikuti oleh 47 siswa SMA X Bandung, namun data yang digunakan adalah data 34 siswa, yang lainnya dianggap tidak valid dan mengalami ketidak lengkapan data kuesionernya. Siswa SMA X Bandung yang menjadi peserta pelatihan dari kelas 12 jurusan IPA terdiri dari $62 \%$ perempuan, lakilakinya $38 \%$, (Gambar 5).

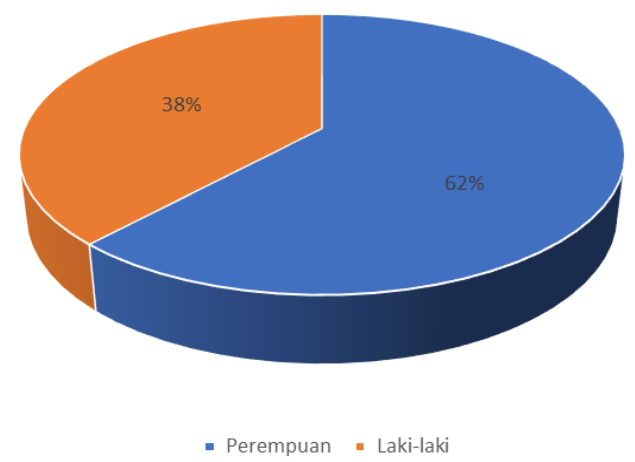

Gambar 5. Pie Jenis Kelamin Peserta

Untuk mengetahui sejauh mana tingkat pengetahuan siswa berkaitan dengan IoT, sebelum dan sesudahmengikuti pelatihan, maka diawal dan di akhir pelatihan, siswa diberikan pre-test dan post-test yang hasilnya ditunjukkan pada Tabel 1 dan dalam bentuk grafik pada Gambar 6,

Tabel 1. Perbandingan hasil pre-test dan pos-test

\begin{tabular}{|c|c|c|c|}
\hline Uraian & Pre Test & Post test & Peningkatan \\
& $(\%)$ & $(\%)$ & $(\%)$ \\
\hline
\end{tabular}


150 | Pengembangan Teknologi IoT Melalui Metode Demonstrasi dan Ekperimen

\begin{tabular}{|l|c|c|c|}
\hline $\begin{array}{l}\text { Pengetahuan dasar tentang IoT dan } \\
\text { penunjangnya }\end{array}$ & 64,25 & 86,75 & 22,50 \\
\hline Pengetahuan tentang jaringan WiFi & 88 & 91 & 3 \\
\hline Pengetahuan tentang Blynk & 71 & 82 & 11 \\
\hline Pengetahuan tentang komponen penunjang & 79 & 82 & 3 \\
\hline \multicolumn{2}{|l|}{ Secara menyeluruh rata-rata peningkatan pengetahuan adalah } & 9,9 \\
\hline
\end{tabular}

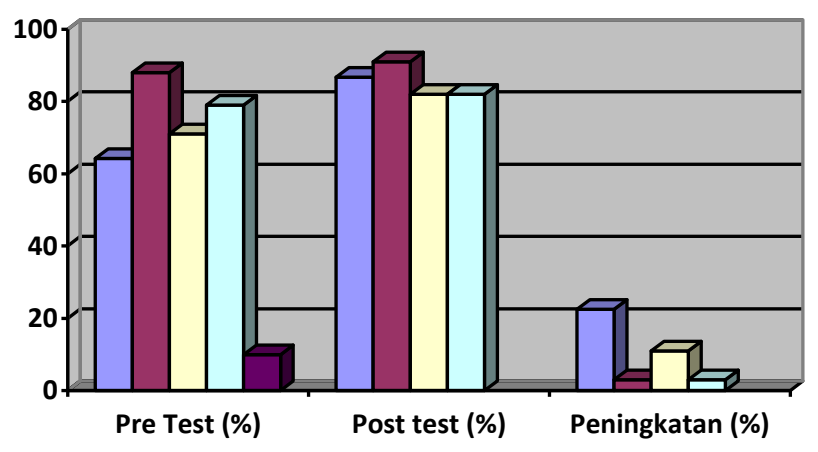

\begin{tabular}{|l|}
\hline Pengetahuan dasar tentang loT dan \\
penunjangnya \\
$\square$ Pengetahuan tentang jaringan WiFi \\
$\square$ Pengetahuan tentang Blynk \\
$\square$ Pengetahuan tentang komponen \\
penunjang \\
$\square$ Secara menyeluruh rata-rata \\
peningkatan pengetahuan adalah
\end{tabular}

Gambar 6. Grafik hasil Pre-test dan Post-test

- Secara umum, Pengetahuan dasar tentang IoT dan penunjangnya (Bahasa pemograman yang digunakan untuk mengaplikasikan teknologi IoT) sudah diketahui dan dipahami oleh siswa, ini terlihat dari hasil tes awal dan pada akhir pelatihan. Pengetahuan Siswa mengalami peningkatan dari $64,25 \%$ yang menjawab benar menjadi $86,75 \%$ yang menjawab dengan benar.

- Secara mendasar siswa sudah mempunyai Pengetahuan tentang jaringan WiFi, hal ini dapat terlihat dari hasil tes awal dan tes akhir pelatihan, yang dalam hal ini mengalami peningkatan dari $88 \%$ yang menjawab benar menjadi $91 \%$ yang menjawab dengan benar.

- Sebagian besar siswa sudah mengetahui tentang Blynk, hal ini dapat terlihat dari jawaban benar yang dilakukan oleh siswa yang kemudian pada akhir pelatihan mengalami peningkatan dari $71 \%$ yang menjawab benar menjadi $82 \%$ yang menjawab dengan benar 
- Sebagian besar siswa sudah memahami tentang komponen penunjang, hal ini dapat terlihat dari jawaban benar pada tes awal, yang kemudian pada akhir pelatihan mengalami peningkatan dari $79 \%$ yang menjawab benar menjadi $82 \%$ yang menjawab dengan benar.

Dari wawancara yang dilakukan pada sebagian siswa peserta, mengatakan bahwa mereka tidak/ belum berminat untuk masuk/ menempuh pendidikan di Program Studi Teknik Elektro, sehingga hal ini menimbulkan asumsi bahwa dengan belum/tidak berminatnya siswa belajar teknik Elektro, maka siswa pun belum/tidak merasa perlu belajar secara mendalam tentang teknologi IoT dan penunjang Teknologi IoT secara khusus seperti komponen-komponen yang digunakan.

\section{Kesimpulan}

Dari hasil pretest dan postest terlihat peningkatan pengetahuan siswa tentang teknologi IoT, walau peningkatan ini tidak terlalu signifikan, karena secara mendasar siswa sudah mengenal tentang teknologi IoT ini, namun untuk mengaplikasikannya yang belum dipahami dengan baik oleh siswa. Secara menyeluruh kegiatan pelatihan dan pembekalan ini direspon siswa peserta secara antusias, hal ini dapat terlihat dengan keseriusan peserta mengikuti kegiatan pelatihan ini sampai selesai. Respon dari peserta setelah selesai mengikuti pelatihan umumnya peserta merasakan manfaatnya, karena pelatihan yang diikuti telah memberikan tambahan pengetahuan bagi peserta. Kualitas pelaksanaan kegiatan baik. Tutor dan asisten cukup membantu peserta untuk memahami materi. Perlu adanya keberlanjutan mengenai pembelajaran aplikasi IoT dengan lebih banyak lagi porsi metode demonstrasi dan eksperimen agar siswa dapat lebih termotivasi lagi akan perlunya teknologi IoT ini, sehingga dapat diaplikasikan secara real dalam kehidupan sehari-hari. 
152 | Pengembangan Teknologi IoT Melalui Metode Demonstrasi dan Ekperimen

\section{Daftar Pustaka}

Afandi, A. (2015). Modul Participatory Action Research (PAR) untuk Pengorganisasian Masyarakat (Community Organizing).

Atoasi, S. (2018). Analisis penerapan smart city dan internet of things (iot) di indonesia, (November).

Ervarica, E. (2015). Penggunaan Metode Demonstrasi dalam Pembelajaran Ajaran IPA untuk Meningkatkan Hasil Belajar Siswa di Sekolah Dasar. Jurnal Pendidikan Dan Pembelajaran, 4, 1-15.

Informatika, K., Penelitian, P., Daya, S., \& Pos, P. (2016). Implementasi Internet Of Things Untuk Sektor Kesehatan. Puslitbang Sumber Daya, Perangkat, dan Penyelenggaraan Pos dan Informatika Badan Penelitian dan Pengembangan Sumber Daya Manusia Kementrian Komunikasi dan Informatika.

Junaidi, A. (2016). Internet of Things, Sejarah , Teknologi Dan Penerapannya. Jurnal Ilmiah Teknologi Informasi, I(AUGUST 2015), 62-66.

Kusumaningrum, A., Pujiastuti, A., \& Zeny, M. (2017). Pemanfaatan Internet of Things Pada Kendali Lampu. Compiler, 6(1), 53-59.

Kusumawati, D., Winarko, B., Wahab, A., \& Pradono, W. (2017). Analisis Kebutuhan Regulasi Terkait dengan Internet of Things Analisis Kebutuhan Regulasi Terkait dengan Internet of Things The Analysis of The Required Regulation of Internet of Things. Buletin Pos Dan Telekomunikasi, 15 No.2(December), 121-138.

Maulidar, W. O. (2013). Penggunaan Metode Eksperimen pada Pembelajaran Materi Sifata Bahan dan Kegunaannya terhadap hasil dan Respon Belajar Siswa Kelas IV Min Tungkob Aceh Besar. Jurnal Ilmiah DIDAKTIK, XIII(2), 336-350.

Meutia, E. D., Teknik, F., \& Syiah, U. (2017). Dampak Sosial Internet of Things. In Seminar Nasional dan Expo Teknik Elektro 2017, ISSN.2088-9984 (pp. 102-106). 
Sinta Dameria Simanjuntak, A. U. (2019). Sinta Dameria Simanjuntak, Ari Usman | 99. Jurnal Soeropati, 2(November), 99-110.

Utami, B. R. P., Arimbawa, I. W. A., \& Bimantoro, F. (2019). Sistem Presensi Siswa berbasis Internet of Things menggunakan Sensor Sidik Jari pada SMK Perhotelan 45 Mataram. Jurnal Teknologi Informasi, Komputer, Dan Aplikasinya (JTIKA ), 1(2). 
154 | Pengembangan Teknologi IoT Melalui Metode Demonstrasi dan Ekperimen 